\title{
Does Dihydromyricetin Impact on Alcohol Metabolism
}

\author{
Aneta SKOTNICOVÁ ${ }^{1}$, Gabriela BOUBÍNOVÁ ${ }^{1}$, Zdislava BOŠTÍKOVÁ ${ }^{1}$, Šárka \\ DUŠKOVÁ ${ }^{3}$, Miroslav ŠULC ${ }^{1}$, Nicolina KUTINOVÁ-CANOVÁ ${ }^{2}, J_{\text {Jaroslav MRÁZ }}^{3}$, Petr \\ HODEK $^{1}$
}

${ }^{1}$ Department of Biochemistry, Faculty of Science, Charles University, Prague, Czech Republic, ${ }^{2}$ Institute of Pharmacology, First Faculty of Medicine, Charles University, Prague, Czech Republic, ${ }^{3}$ Centre of Occupational Health, National Institute of Public Health, Prague, Czech Republic

Received October 8, 2020

Accepted October 16, 2020

\section{Summary}

Dihydromyricetin (DHM) is a natural flavonoid showing several health promoting effects such as protective activity during severe alcohol intoxication. The mechanism underlying the effects of DHM on alcohol metabolism is virtually unknown. The present paper is focused on clarifying the role of DHM in the liver alcohol elimination at its molecular level. First, impact of DHM on alcohol dehydrogenase $(\mathrm{ADH})$ activity in vitro and the enzyme induction in vivo was examined. Neither the $\mathrm{ADH}$ activity nor the enzyme expression were influenced by DHM. Next, the effect of DHM during alcohol intoxication were studied on primary hepatocytes isolated from EtOH-premedicated and untreated rats. The viability of cells exposed to alcohol, estimated based on the released enzymes, alanine aminotransferase (ALT) and aspartate aminotransferase (AST), was slightly affected by DHM. Although the expected hepatoprotective effect of DHM was not fully achieved, DHM (in a concentration manner) proved to reduce the level of ROS/RNS in hepatocytes. However, no change in the rate of alcohol metabolism in vivo was found when rats were administered with a single or repeated dose of ethanol supplemented with DHM. In conclusion, the proposed positive effect of DHM during alcohol intoxication has not been proven. Moreover, there is no effect of DHM on the alcohol metabolism. The "hoped-for" DHM hepatoprotective activity can be attributed to the reduction of ROS/RNS levels in cells.

\section{Key words}

Alcohol dehydrogenase • Hepatocytes • Flavonoid

\section{Corresponding author}

P. Hodek, Department of Biochemistry, Faculty of Science, Charles University, Hlavova 8/2030, CZ 12840 Prague 2, Czech Republic. E-mail: hodek@natur.cuni.cz

\section{Introduction}

Dihydromyricetin (DHM), also known as ampelopsin, is a natural flavonoid compound, which is found in large quantities in Asian plant species. One of them - Hovenia dulcis - is known for centuries in traditional Chinese medicine as a cure for alcohol poisoning and hangover (Liang et al. 2014).

Dihydromyricetin, like other flavonoid compounds, is known for several effects on the human body. DHM has an anti-inflammatory, cardioprotective or dermaprotective effect. By affecting cholesterol metabolism, DHM inhibits the onset of atherosclerosis. Positive effects on insulin resistance are related to its ability to lower glucose levels in the blood. Thus, dihydromyricetin suppresses diabetic cardiomyopathy. And most importantly, DHM has been shown to provide significant hepatoprotective effects. Its positive influence on alcohol-induced and other liver diseases was suggested in the study of acute liver failure (Liu et al. 2017).

The impact of DHM on ethanol consumption is explained in terms of the competitive inhibition of the benzodiazepine sites on GABA receptors. It was published that ethanol intoxication of the experimental rats was reduced by administration of DHM, and the symptoms of alcohol withdrawal syndrome were mitigated (Shen et al. 2012). The hepatoprotective effect of DHM is likely connected with its ability to protect liver cells against reactive oxygen species (ROS) and inflammatory reactions in the organism. Studies on human umbilical vein endothelial cells and on human liver cancer cell line (HepG2) proved that DHM affects 
the regulatory mechanisms in the liver cells which can cause the decrease of ROS level (Hou et al. 2015, Silva et al. 2020).

The data show that DHM, when used as a dietary supplement, helps to reduce oxidation damage of hepatocytes. The mechanism of hepatoprotective effects against alcohol is not yet completely understood. The studies were mostly carried out with an inaccurate experimental model such as HepG2 cells which does not have functional enzymes for oxidative metabolism of EtOH (Silva et al. 2020).

Another study using hepatoblastoma cells, as a model, shows that supplementation with DHM significantly increases the activity and expression of alcohol dehydrogenase and aldehyde dehydrogenase (Silva et al. 2020). Interestingly, the expression of CYP2E1, the enzyme, which is also involved in the metabolism of ethanol, especially during chronic ethanol consumption, was significantly reduced by DHM in the mice model (Silva et al. 2020, Zakhari 2006).

Even though it appears that DHM health promoting activity is probably due to a reduction of oxidative stress, the role of DHM in ethanol metabolism is still unknown. Although several hypotheses have been suggested, the exact mechanism has not been found yet.

The aim of this study is to determine the impact of DHM on ADH, CYP2E1 and ethanol metabolism in vivo, under conditions closely mimicking human alcohol consumption, and to reveal a possible hepatoprotective effect of this flavonoid.

\section{Methods - Materials}

\section{Materials}

Rabbit monoclonal antibody to alcohol dehydrogenase and rabbit monoclonal antibody to CYP2E1 were obtained from Abcam (UK), dihydromyricetin from APIChem (China), reagents for Western Blot from Bio-Rad (USA), ${ }^{\mathrm{L}} \mathrm{ALT}$ (GPT) kit, ${ }^{\mathrm{L}} \mathrm{AST}$ (GOT) kit, ${ }^{\mathrm{D}}$ Biocal standard from Biovendor (Czech Republic), NAD ${ }^{+}$from Cambrian Chemicals (Canada) and FBS from Gibco ${ }^{\circledR}$ by Life TechnologiesTM (USA). Collagen and NADH were provided by ROCHE s.r.o., Diagnostic Division (Germany), heparin and collagenase by Zentiva Group, a.s. (Netherlands) and all other used reagents and chemicals of reagent grade or better were purchased from SigmaAldrich (Czech Republic).
Animals

Male Wistar rats (300-400 g body weight) (AnLab, Czech Republic) were used for all experiments in this study. Animals were allowed tap water and standard granulated diet ad libitum and were maintained under the standard conditions - light (12/12-h dark/light), temperature $\left(20 \pm 2{ }^{\circ} \mathrm{C}\right)$ and relative humidity $(50 \pm 100 \%)$. The study was conducted in accordance with the Regulations for the Care and Use of Laboratory Animals (419/2019, Ministry of Agriculture, Czech Republic) which is in compliance with the Declaration of Helsinki.

\section{Preparation of primary hepatocyte cell culture}

Primary hepatocytes were isolated from rats premedicated by gastric gavage with $40 \%$ EtOH diluted in PBS ( $3 \mathrm{~g} / \mathrm{kg}$ body weight) for four consecutive days and $20 \% \mathrm{EtOH}$ was available as an only resource of water for two days before isolation. Rats from a control group were premedicated by gastric gavage with PBS.

The standard two-phase collagenase perfusion (Moldeus et al. 1978) with minor modifications (Farghali et al. 1986) was used for hepatocytes isolation. Bürker chamber was used for the counting hepatocytes and the cell viability was determined via Trypan blue exclusion method (Strober 2001).

Primary hepatocytes were cultivate using William's medium containing $5 \%$ FBS, 2 mM L-glutamine, $6 \mu \mathrm{g} / \mathrm{ml}$ insulin, $100 \mu \mathrm{g} / \mathrm{ml}$ streptomycin, and $100 \mathrm{IU} / \mathrm{ml}$ penicillin. Hepatocytes were diluted to the final concentration of $6.7 \times 10^{5}$ viable cells $/ \mathrm{ml}$ medium and were cultivated in collagen coated 6 or 24 wells with a density of $10^{4}$ cells $/ \mathrm{cm}^{2}$. Cultivation of cells took place at standard conditions $\left(37{ }^{\circ} \mathrm{C}, 95 \%\right.$ air, and $\left.5 \% \mathrm{CO}_{2}\right)$ for three hours in the incubator SANYO MCO-20 AIC. After that medium was replaced for a fresh one and nonadherent hepatocytes were removed. The cultivation of cells continued for another $21 \mathrm{~h}$ under the standard conditions as described above. Then, the medium was replaced with medium lacking FBS with tested compounds added. The first group contained LPS in final concentration $15 \mu \mathrm{g} / \mathrm{ml}$ and the second ethanol in final concentrations $100-800 \mathrm{mM}$ with or without dihydromyricetin in final concentrations $1-1000 \mu \mathrm{M}$. Because of alcohol evaporation EtOH was added after $7 \mathrm{~h}$. Cultivation continued again for approx. $15 \mathrm{~h}$ under the standard conditions.

Then hepatocytes were washed two times with ice-cold PBS and harvested by scraping. Cells were spin down at $5000 \mathrm{RPM}$ for $5 \mathrm{~min}$ at $4{ }^{\circ} \mathrm{C}$ (Spectrafuge 
C1301B). The pellets were immediately frozen in liquid nitrogen and stored at $-80{ }^{\circ} \mathrm{C}$. Protein concentration of samples was determinate using Lowry method (Lowry et al. 1951) with minor modifications (Hartree 1972). The medium (collected last day) was used for determination of ALT and AST.

\section{Cell viability assays}

Cytotoxicity of tested compounds was determined using MTT test (Mosmann 1983) as well as based on the concentration of released enzymes, ALT and AST, in the medium. For the determination of concentration of ALT and AST commercial tests ( ${ }^{\mathrm{L}}$ ALT (GPT) kit, ${ }^{\mathrm{L}}$ AST (GOT) kit) were used. Enzyme concentrations were determined in medium collected from 6-WP last day of primary hepatocyte cultivation. Groups of hepatocytes cultivated in medium containing EtOH and with or without DHM were used. MTT test and enzyme assays were carried out in triplicates.

\section{Determination of ROS in primary hepatocytes}

Hepatocytes cultivated on 24-WP were washed with cold PBS and incubated with $20 \mu \mathrm{M}$ DCFDA for 60 min under $37^{\circ} \mathrm{C}$ in the dark (Chen et al. 2010, LeBel et al. 1992). The fluorescence intensity was measured at 485/535 nm, Ex/Em (Infinite $\AA 200$ PRO, Tecan Trading AG, Switzerland). The results were standardized to the number of cells seeded and related to the control group.

\section{Activity of alcohol dehydrogenase}

Alcohol dehydrogenase catalyzes the oxidation of ethanol to acetaldehyde in the presence of cofactor $\mathrm{NAD}^{+}$, which is reduced to NADH. To determine activity of alcohol dehydrogenase in samples of hepatocytes the increase of absorbance at $340 \mathrm{~nm}$ every two minutes for 60 min under $37^{\circ} \mathrm{C}$ and constant shaking was measured (Program medium shaking, Multiskan GO). In brief, the reaction mixture contained $82 \mu \mathrm{l}$ of $0.1 \mathrm{M}$ phosphate buffer $\mathrm{pH} 7.4 ; 8 \mu \mathrm{l}$ of $10 \mathrm{mM} \mathrm{NAD}^{+} ; 50 \mu \mathrm{l}$ of samples $(1 \mathrm{mg} / \mathrm{ml})$ in $150 \mu \mathrm{l}$ final volume and was started by addition of $10 \mu \mathrm{l}$ of EtOH. Enzyme activity was calculated based on a calibration curve.

\section{Determination of CYP2E1 activity}

Activity of CYP2E1 was determined based on 6-hydroxylation of chlorzoxazone, a specific substrate of CYP2E1. To follow the formation of 6-hydroxychlorzoxane the HPLC (Agilent Technologies 1200, USA) equipped with $\mathrm{C} 18$ column (Macherey-Nagel, Nucleosil
100-5 column C18) was used (Peter et al. 1990).

\section{Western blot analysis}

Discontinuous SDS-PAGE analysis using MiniPROTEAN® Tetra Cel (Bio-Rad, USA) was performed (Laemmli 1970). Samples of hepatocytes or cytosolic samples from liver $(40 \mu \mathrm{g})$ prepared in reducing sample buffer were separated in a $10 \%$ polyacrylamide gel at $200 \mathrm{~V}$. The transfer of separated proteins onto PVDF membranes was carried out at $0.8 \mathrm{~mA} / \mathrm{cm}^{2}$ for $10 \mathrm{~min}$ and to $2 \mathrm{~mA} / \mathrm{cm}^{2}$ for $45 \mathrm{~min}$. Membranes were incubated with primary rabbit antibody against alcohol dehydrogenase and against CYP2E1, respectively and diluted 1:1000, 1:5000 respectively and then with secondary goat anti-rabbit IgG-alkaline phosphatase conjugate diluted 1:1428. For visualization of a specific protein band the membrane was incubated in developing solution (SigmaFast tablet dissolved in $10 \mathrm{ml}$ of distilled water) for $5 \mathrm{~min}$.

\section{Alcohol metabolism in vivo}

Rats were separated into two groups $(n=4)$ and premedicated by gastric gavage with $40 \% \mathrm{EtOH}$ or with combination of $40 \% \mathrm{EtOH}$ and DHM $(10 \mathrm{mg} / \mathrm{kg}$ body weight). Animals were fasted for approx. $16 \mathrm{~h}$ before premedication. Blood of all animals was collected from eye in 5, 15, 30 and $60 \mathrm{~min}$ from the gastric gavage. The concentrations of ethanol and acetaldehyde in full blood samples were measured immediately using headspace-gas chromatography (in triplicates).

After $24 \mathrm{~h}$, half of rats of both groups $(n=2)$ were repeatedly premedicated by gastric gavage with $40 \%$ EtOH again. Blood sample collection and measuring of concentrations of ethanol and acetaldehyde proceeded similarly to the procedure described above. All samples were measured at Institute of Forensic Medicine and Toxicology, Branch of Toxicology, Ke Karlovu 2, 12808 Prague 2, Czech Republic.

\section{Preparation of liver microsomal and cytosolic fractions}

Standard differential centrifugation procedure was used for isolation of cytosolic fractions (Hodek et al. 2011, Krizkova et al. 2008). The whole procedure was carried out in a cold room at $4{ }^{\circ} \mathrm{C}$. All materials and buffers were cooled down before using.

In brief, liver tissues were washed and homogenized in $0.1 \mathrm{M}$ Tris- $\mathrm{HCl}$ buffer $\mathrm{pH} 7.4$ with $50 \mu \mathrm{M}$ tocopherol (from methanol stock) in a PotterElvehjem homogenizer and centrifuged at $600 \times \mathrm{g}$ for 
10 min (383K, HERMLE). Pellets were rehomogenized under the same conditions. Subsequently, supernatants from both centrifugations were pooled and centrifuged at $15000 \times \mathrm{g}$ for $20 \mathrm{~min}$ (Allegra X-30R, Beckman Coulter). Then supernatants were ultracentrifuged at $123000 \times \mathrm{g}$ for 90 min (Optima XPN-90, Beckman Coulter). Collected microsomal and cytosolic fractions were immediately frozen and stored at $-80{ }^{\circ} \mathrm{C}$.

\section{Statistics}

Statistical analyses were performed using Student's $t$-test and approximated with Welch's $t$-test. Means \pm standard deviations of parallel experiments are shown and $\mathrm{P}<0.05$ were considered as significant.

\section{Results and Discussion}

To study the effect of DHM on ethanol metabolism introductory ex vivo experiments using primary hepatocytes isolated from EtOH-premedicated and untreated rats were performed. Cells were exposed to ethanol and DHM. Markers of liver damage (ALT and AST) were used for testing the cell viability along with MTT test and the determination of ROS. Next, an impact of DHM on ADH and CYP2E1 was examined on the level of protein expression, protection and modulation of the enzyme activity. Finally, in vivo experiments with rats simultaneously treated with EtOH and DHM were performed. Ethanol metabolism was monitored based on the concentration of ethanol and acetaldehyde in full blood.

\section{Effect of DHM on viability of primary hepatocytes}

The cell viability and degree of damage of primary hepatocytes were determinate using MTT test and based on the amount of enzymes - ALT and AST, known markers of liver damage. Released ALT and AST were measured using their enzyme activity (Fig. 1).

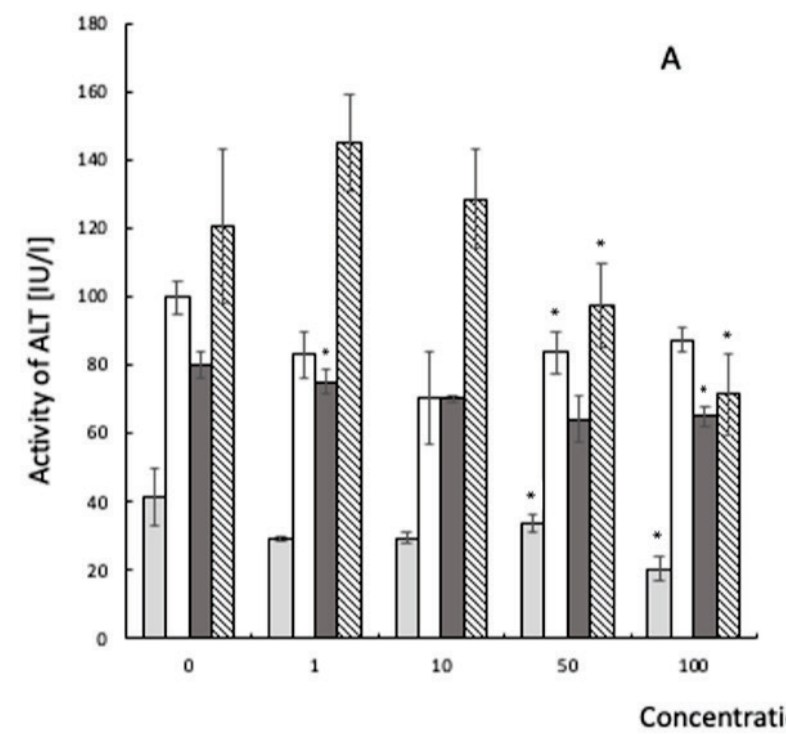

$\square$ Untreated rat, cultivated in medium without $\mathrm{EtOH}$
$\square$ EtOH-premedicated rat, cultivated in medium without EtOH

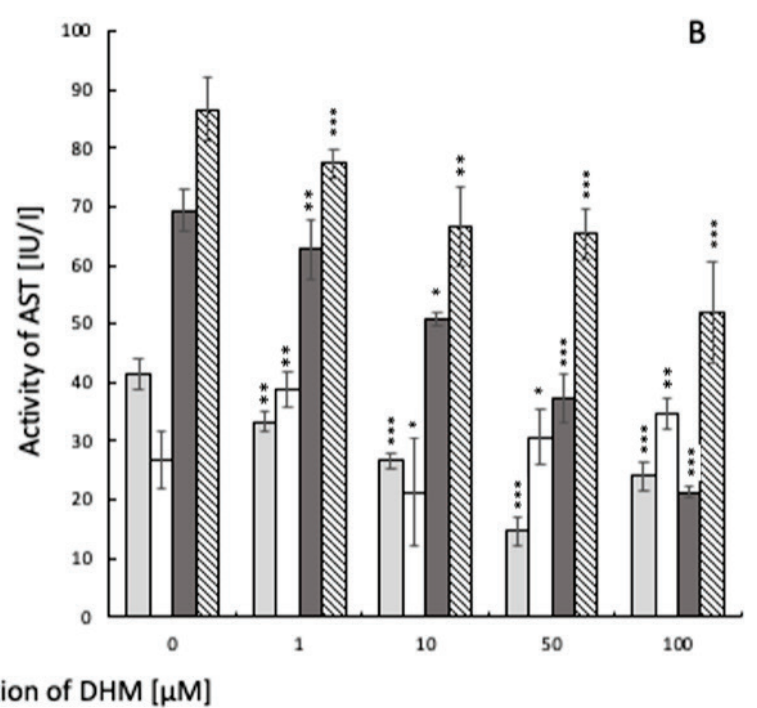

口Untreated rat, cultivated in medium with EtOH \& EtOH-premedicated rat, cultivated in medium with $\mathrm{EtOH}$

Fig. 1. Effect of DHM on activity of released ALT/AST. Concentrations of ALT (A) and AST (B) were measured in medium of hepatocytes isolated from EtOH-premedicated and untreated rats with or without EtOH. Primary hepatocytes were incubated in medium with 1-100 $\mu \mathrm{M}$ DHM in the presence or absence of $300 \mathrm{mM}$ EtOH. Medium was collected from 6-WP. All samples were measured in triplicates. Data are means \pm standard deviations of parallel experiments; $P<0.05$ were considered as significant $(* P<0.05, * * P<0.01$ and $* * * \mathrm{P}<0.001)$.

Data in Figure 1 show differences in the cell viability among primary hepatocytes isolated from EtOHpremedicated and untreated rats cultivated in medium with or without EtOH. In general, hepatocytes isolated from EtOH-premedicated rats had lower viability compared to hepatocytes isolated from control groups (data not shown). This observation is in agreement with results of determination of ALT and AST (Fig. 1). Activities of these two enzymes were higher in EtOH-premedicated groups. As data show the presence of DHM in a concentration-dependent manner slightly reduced the level of released enzymes. This hepatoprotective effect of DHM has been also reported by others (Jiang et al. 2015, Murakami et al. 2004). 
Effect of DHM on alcohol dehydrogenase and CYP2E1 activity

The activity of recombinant equine alcohol dehydrogenase was determined at increasing concentration of DHM. As shown in Figure 2A DHM in concentrations 10 and $100 \mu \mathrm{M}$ did not affect the activity of $\mathrm{ADH}$. Some extent of inhibition is apparent at the highest DHM concentrations $(1000 \mu \mathrm{M})$.

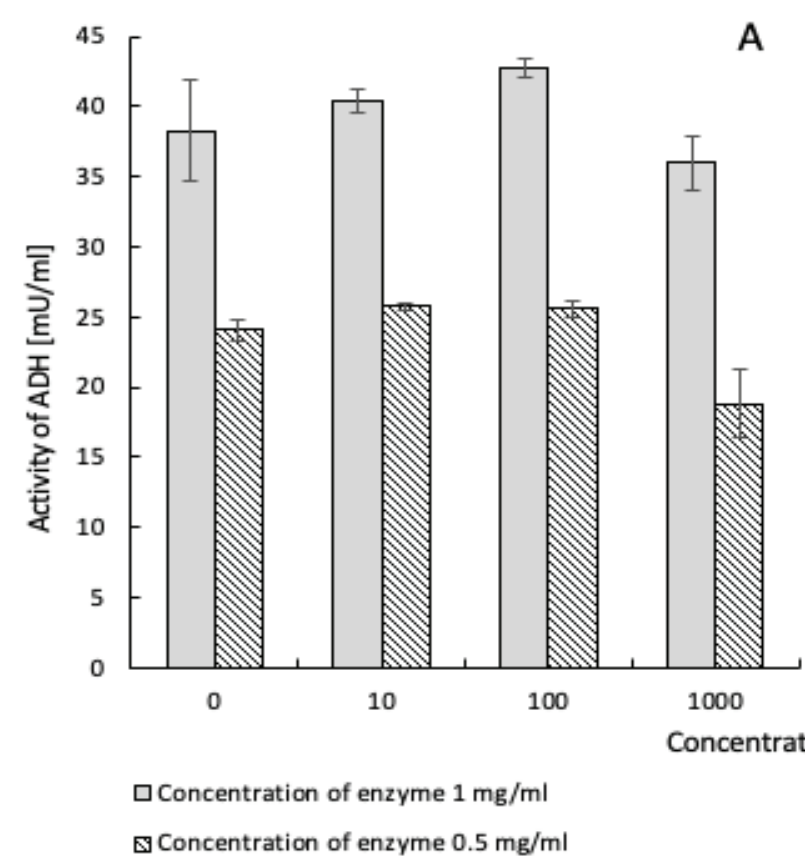

Fig. 2. Effect of DHM on activity of $A D H$. The assay was carried out with recombinant equine alcohol dehydrogenase $(\mathbf{A})$ and alcohol dehydrogenase in primary hepatocytes isolated from EtOH-premedicated and untreated rats (B). The amount of reduced NADH cofactor was determined spectrophotometrically at $340 \mathrm{~nm}$ for $60 \mathrm{~min}$ (A). Same as described in previous figure (B). The reaction was monitored as an increase of absorbance in time. Enzyme activity was determined based on the calibration curve. All samples were measured in triplicates. Data are means \pm standard deviations of parallel experiments; $\mathrm{P}<0.05$ were considered as significant $(* \mathrm{P}<0.05, * * P<0.01$ and $* * * P<0.001)$.

The effect of DHM on activity of $\mathrm{ADH}$ was determined also in primary hepatocytes isolated from EtOH-premedicated and untreated rats (Fig. 2B). Preliminary experiments with primary hepatocytes show that concentration $1000 \mu \mathrm{M}$ of DHM is lethal for cells, thus, such high concentration of DHM was not used for further experiments. The ADH activity was monitored depending on the concentrations of DHM or EtOH added to the cultivation medium. Figure 2 shows that DHM has no significant influence on the activity of ADH. Hence, the published data showing DHM as an agent which can increase the metabolic rate of alcohol degradation in the body (Shen et al. 2012), cannot be attributed to the $\mathrm{ADH}$ activity stimulation by this flavonoid.

Moreover, the effect of DHM on the metabolic activity of CYP2E1, the second most important enzyme involved in the metabolism of ethanol, was examined. Up to $100 \mu \mathrm{M}$ concentration DHM did not affect CYP2E1 mediated 6-hydroxylation of chlorzoxazone.
Effect of DHM on expression of alcohol dehydrogenase and cytochrome P450 2E1

Alternatively, the effect of DHM on alcohol metabolism might be associated with the induction of $\mathrm{ADH}$ and/or CYP2E1 in liver. The expression of $\mathrm{ADH}$ and CYP2E1 were examined at its protein level by Western blot technique. Data show that DHM has no effect on the expression of ADH and CYP2E1 at in vivo experiments (data not shown).

Determination of the level of ROS/RNS in primary hepatocytes

To test the hypothesis that DHM impacts the alcohol metabolism via its hepatoprotective properties, the antioxidant effect of DHM on primary rat hepatocytes was examined using a fluorescent probe, $2^{\prime}, 7^{\prime}$-dichlorofluorescin diacetate (DCFDA). This probe is the most commonly used for determination of total level of ROS/RNS in the cells (LeBel et al. 1992). 


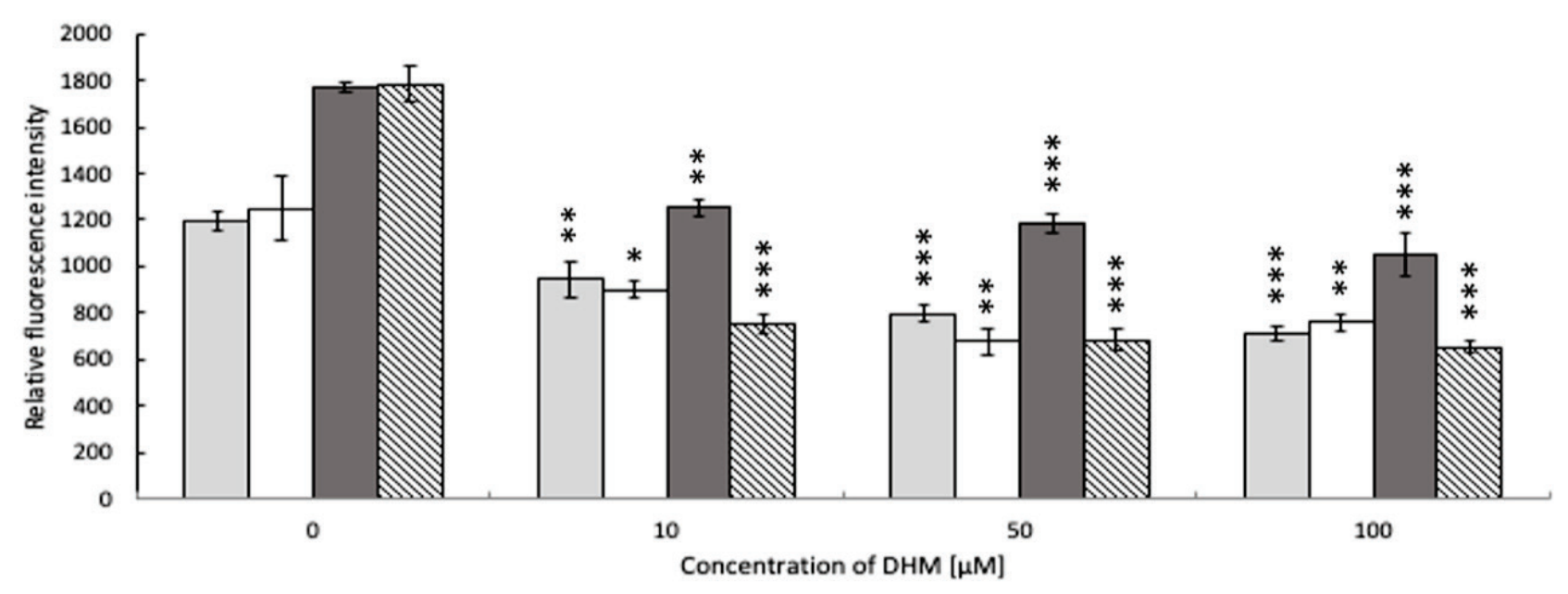

口Untreated rat, cultivated in medium without $\mathrm{EtOH}$

口Untreated rat, cultivated in medium with $\mathrm{EtOH}$

$\square \mathrm{EtOH}$-premedic ated rat, cultivated in medium without $\mathrm{EtOH}$

$\mathbb{Q}$ EtoH-premedicated rat, cultivated in medium with $\mathrm{EtOH}$

Fig. 3. Effect of DHM on level of ROS/RNS in primary hepatocytes. Cells were isolated from EtOH-premedicated and untreated rats. ROS/RNS was measured in 24-WP after 60 min incubation with DCFDA at $37^{\circ} \mathrm{C}$ in the dark. The fluorescence intensity was measured at 485/535 nm, Ex/Em (Infinite $® 200$ PRO, Tecan Trading). Six wells were measured for each group. Data are means \pm standard deviations of parallel experiments; $\mathrm{P}<0.05$ were considered as significant $(* \mathrm{P}<0.05, * * \mathrm{P}<0.01$ and $* * * P<0.001)$.

Results shown in Figure 3 confirmed presumption that DHM is able to decrease the level of ROS/RNS in primary hepatocytes (Silva et al. 2020). Hepatocytes isolated from EtOH-premedicated rats had significantly higher level of relative intensity of fluorescence compared to cells isolated from untreated rats. This observation accounts for a cell damage induced by EtOH-premedication. Hepatocytes isolated from EtOH-premedicated rats incubated with $300 \mathrm{mM}$ EtOH did not show a proportional dependence of ROS/RNS levels with the increase of DHM concentration. The most marked decrease of ROS/RNS levels was caused by 10-50 $\mu \mathrm{M}$ DHM. The adaptation of cells to ethanol or ability of $\mathrm{EtOH}$ to scavenge radicals, resulting in reduction of the amount of ROS/RNS in cells may explain this observation. Moreover, it was published that DHM regulates level of ROS via liver catalase (Silva et al. 2020). Another study also confirmed ability of DHM to lower the level of ROS and to induce apoptosis in HepG2 (Liu et al. 2014).

\section{Effect of DHM on metabolism of ethanol in vivo}

The proposed impact of DHM on the acceleration of ethanol metabolism was finally tested in rats. Rats were divided into two groups. First group received $40 \%$ ethanol by gastric gavage while the second group was premedicated with a $40 \% \mathrm{EtOH}$ containing DHM (10 mg/kg body weight). Within $60 \mathrm{~min}$ from the animal treatment the blood was collected from the eye of the rats. The amount of EtOH and acetaldehyde in the blood was determined. Data show that DHM does not significantly affect the EtOH metabolism rate (Fig. 4A, C). Next, the effect of DHM on repeated application of EtOH was examined after $24 \mathrm{~h}$. Both groups were administered with $40 \% \mathrm{EtOH}$ and the amounts of EtOH and acetaldehyde were determined in collected blood. Amount of EtOH was markedly higher in the blood of rats being premedicated the first day with DHM compared to rats that were administered with EtOH, only (Fig. 4B, D). Our results of a single EtOH administration experiment did not confirm the data presented by Shen et al. (2012).

As it is clear from Figure 4, DHM does not decrease concentration of either EtOH or acetaldehyde in the blood. A sole decrease of EtOH concentration (time $30 \mathrm{~min}$ ) is not statistically significant (group of DHMpremedicated rats). The reason for these diverse results between our and Shen's studies might be caused by different method of administration of EtOH and DHM. In our experiment the gastric gavage of $\mathrm{EtOH}$ (which simulates better the real human intake) was used while Shen et al. (2012) administered EtOH intraperitoneally. The recent findings indicate the use of intraperitoneal administration for the purpose of studying the metabolism of EtOH as inappropriate (Silva et al. 2020). Thus our data show that DHM do not speed up the alcohol metabolism but even slows down this process when alcohol was repeatedly administered. 


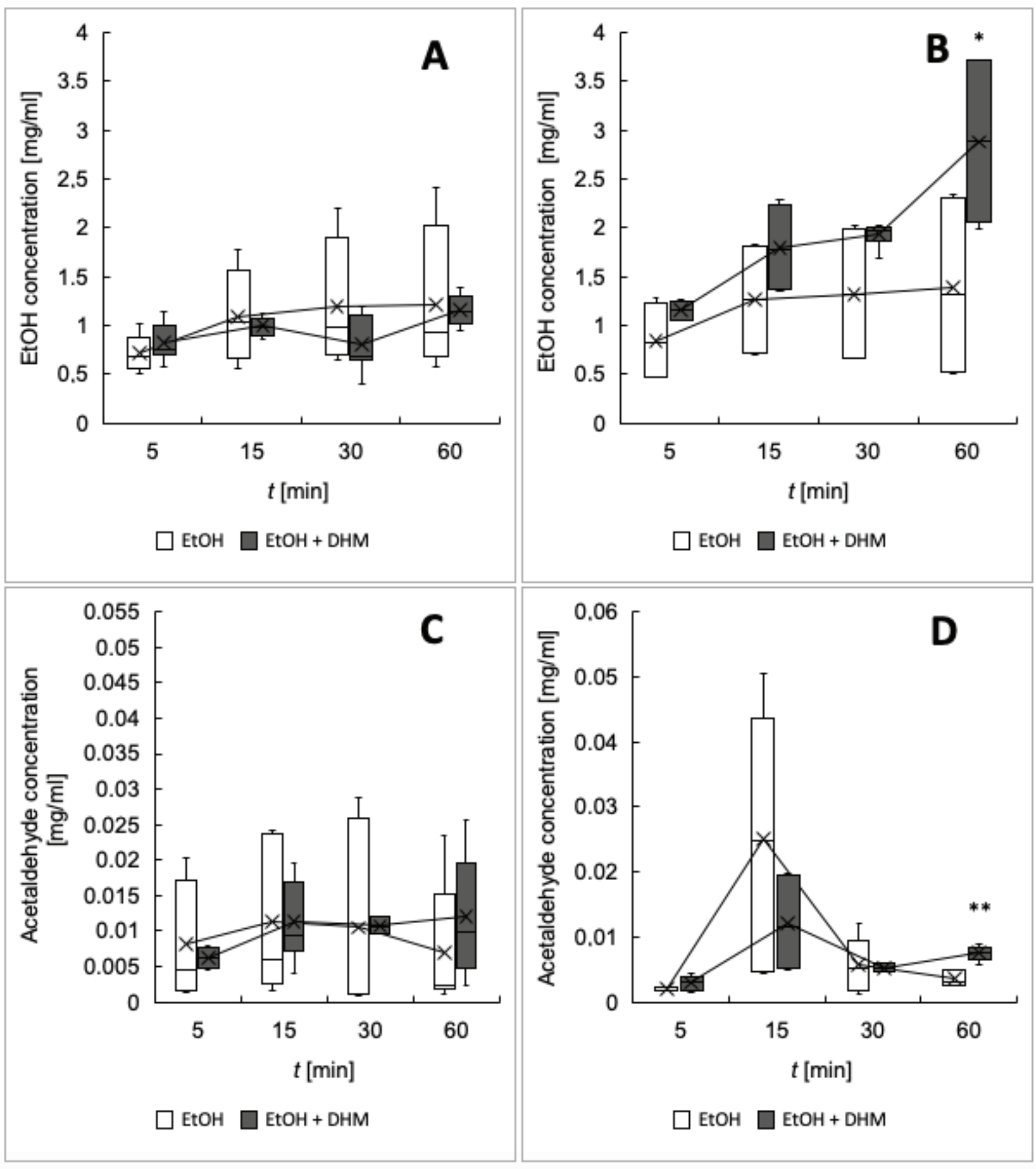

Fig. 4. Effect of DHM on ethanol metabolism. After the first gastric gavage of ethanol/DHM concentrations of ethanol (A) and acetaldehyde (C) was determined in blood samples from rats $(n=4)$. Concentrations of ethanol $(\mathbf{B})$ and acetaldehyde (D) in blood samples from rats $(n=2)$ was also determined after the second premedication with $\mathrm{EtOH}$ only. Blood samples were collected and immediately measured (in triplicates) by headspace-gas chromatography. Data are means \pm standard deviations of parallel experiments; $\mathrm{P}<0.05$ were considered as significant $(* \mathrm{P}<0.05$, $* * \mathrm{P}<0.01$ and $* * * \mathrm{P}<0.001)$.

\section{Conclusions}

Regardless our concentrated effort we were not able to reveal the basic of DHM effect on ethanol metabolism if there is any. Our data show that suggested hepatoprotective effect of DHM during alcohol intoxication cannot be attributed to the modulation of ADH or CYP2E1 activities at any level. Thus, the exact mechanism underlying the hepatoprotective properties of DHM is still not fully understood. However, we cannot exclude that DHM-mediated reduction of oxidative stress is partially involved. 


\section{Conflict of Interest}

There is no conflict of interest.

\section{Acknowledgements}

This study was supported by the grant P303/12/G163 from Grant Agency of the Czech Republic. We are grateful to Radomír Čabala for his help with measuring of ethanol and acetaldehyde in blood samples and for help with evaluation of results.

\section{References}

CHEN X, ZHONG Z, XU Z, CHEN L, WANG Y: 2',7'-Dichlorodihydrofluorescein as a fluorescent probe for reactive oxygen species measurement: Forty years of application and controversy. Free Radic Res 44: 587-604, 2010. https://doi.org/10.3109/10715761003709802

FARGHALI H, BUCHAR E, MACHKOVA Z, KAMENIKOVA L, MASEK K: Muramyl dipeptide and carbon tetrachloride hepatotoxicity in rats: involvement of plasma membrane and calcium homeostasis in protective effect. Methods Find Exp Clin Pharmacol 8: 469-477, 1986.

HARTREE EF: Determination of protein: a modification of the Lowry method that gives a linear photometric response. Anal Biochem 48: 422-427, 1972. https://doi.org/10.1016/0003-2697(72)90094-2

HODEK P, KRIZKOVA J, FREI E, SINGGH R, ARTL VM, STIBOROVA M: Impact of beta-naphthoflavone on genotoxicity of food-derived carcinogens. Neuro Edocrinol Lett 32 (Suppl 1): 25-34, 2011.

HOU X, TONG Q, WANG W, XIONG W, SHI C, FANG J: Dihydromyricetin protects endothelial cells from hydrogen peroxide-induced oxidative stress damage by regulating mitochondrial pathways. Life Sci 130: 38-46, 2015. https://doi.org/10.1016/j.lfs.2015.03.007

JIANG L, ZHANG Q, REN H, MA S, LU CJ, LIU B, LIU J, LIANG J, LI M, ZHU R: Dihydromyricetin enhances the chemo-sensitivity of nedaplatin via regulation of the p53/Bcl-2 pathway in hepatocellular carcinoma cells. PloS One 10: e0124994, 2015. https://doi.org/10.1371/journal.pone.0124994

KRIZKOVA J, BURDOVA K, HUDECEK J, STIBOROVA M, HODEK P: Induction of cytochromes P450 in small intestine by chemopreventive compounds. Neuro Endocrinol Lett 29: 717-721, 2008.

LEBEL CP, ISCHIROPOULOS H, BONDY SC: Evaluation of the probe 2',7'-dichlorofluorescin as an indicator of reactive oxygen species formation and oxidative stress. Chem Res Toxicol 5: 227-231, 1992. https://doi.org/10.1021/tx00026a012

LIANG J, OLSEN RW: Alcohol use disorders and current pharmacological therapies: the role of GABAA receptors. Acta Pharmacol Sin 35: 981-993, 2014. https://doi.org/10.1038/aps.2014.50

LIU B, TAN X, LIANG J, WU S, LIU J, ZHANG Q, ZHU R: A reduction in reactive oxygen species contributes to dihydromyricetin-induced apoptosis in human hepatocellular carcinoma cells. Sci Rep 4: 7041, 2014. https://doi.org/10.1038/srep07041

LIU Z, YANG K, CHEN Z, CHENG Q, WU L: The versatile effects of dihydromyricetin in health. Evid Based Complement Alternat Med 6: 1053617, 2017. https://doi.org/10.1155/2017/1053617

LOWRY O, ROSEBROUGH N, FARR A, RANDALL R: Protein measurement with the Folin phenol reagent. J Biol Chem 193: 265-275, 1951.

MOLDEUS P, HOGBERG J, ORRENIUS S: Isolation and use of liver cell. Methods Enzymol 52: 60-71, 1978. https://doi.org/10.1016/S0076-6879(78)52006-5

MOSMANN T: Rapid colorimetric assay for cellular growth and survival: application to proliferation and cytotoxicity assays. J Immunol Methods 65: 55-63, 1983. https://doi.org/10.1016/0022-1759(83)90303-4

MURAKAMI T, MIYAKOSHI M, ARAHO D, MIZUTANI K, KAMBARA T, IKEDA T, CHOU WH, INUKAI M, TAKENAKA A, IGARASHI K: Hepatoprotective activity of tocha, the stems and leaves of Ampelopsis grossedentata, and ampelopsin. Biofactors 21: 175-178, 2004. https://doi.org/10.1002/biof.552210136

PETER R, BÖCKER R, BEAUNE PH, IWASAKI M, GUENGERICH FP, YANG CS: Hydroxylation of chlorzoxazone as a specific probe for human liver cytochrome P-450IIE1. Chem Res Toxicol 3: 566-573, 1990. https://doi.org/10.1021/tx00018a012 
SHEN Y, LINDEMEYER AK, GONZALEZ C, SHAO XM, SPIGELMAN I, OLSEN RW, LIANG, J: Dihydromyricetin as a novel anti-alcohol intoxication medication. J Neurosci 32: 390-401, 2012. https://doi.org/10.1523/JNEUROSCI.4639-11.2012

SILVA J, YU X, MORADIAN R, FOLK C, SPATZ MH, KIM P, BHATTI AA, DAVIES DL, LIANG J: Dihydromyricetin protects the liver via changes in lipid metabolism and enhanced ethanol metabolism. Alcohol Clin Exp Res 44: 1046-1060, 2020. https://doi.org/10.1111/acer.14326

STROBER W: Trypan blue exclusion test of cell viability. Curr Protoc Immunol 111: 3, 2001. https://doi.org/10.1002/0471142735.ima03bs21

ZAKHARI S: Overview: how is alcohol metabolized by the body? Natl Inst Alcohol Abuse Alcohol 29: $245-254,2006$. https://doi.org/10.1159/000095013 